\title{
A UNITED NATIONS EDUCATIONAL AND CULTURAL ORGANISATION
}

\section{INTRODUCTION}

By DR. E. F. ARMSTRONG, F.R.S.

Adviser to Delegates of H.M. Government

$T$ HE United Nations Educational and Cultural Conference that opened in London on November 1 has been called to prepare the establishment of a United Nations Organisation for promoting educational and cultural co-operation.

It is natural that a new effort towards world cooperation in the cultural field should occur after the devastations of the Second World War. We wish to repair the damage to our friends and ourselves as quickly as possible.

This is particularly serious in the cultural field. The damage that the enemy has done to things of the mind is even more appalling than the terrible material destruction for which he is responsible. Vile ideas have been instilled into the young, and the best traditions of research and learning have been debased.

The chief way by which the victims can be restored to eivilization is by education and rehabilitation. It is, however, impossible to teach and to train the mind in research and rational inquiry without schools, and apparatus and laboratories.

One of the main aims of the Conference will be to create an Organisation that will help to achieve this restoration.

A second matter of equal importance is the promotion of educational, scientific and cultural cooperation in the future. Men of science will expect that due weight should be given to science in the conceptions and machinery of the new Organisation.

The place of science in the structure and outlook of modern civilization has been growing steadily for generations. Almost every aspect of production, transport, nutrition, health and the primary needs of life are dependent on it. The influence on modes of thought in research and learning, and spiritual attitudes, is equally great. The application of the scientific mode of thought to the problems of man and society is perhaps our chief hope for the future. But we cannot utilize it if we do not know what it is. We want to see the restoration and improvement of education, with appropriate weight given to science, in view of its contemporary importance.

The latest developments of atomic energy make the need for the understanding and use of science yet a thousandfold greater.

Thus it is profoundly necessary that seience should have due place both in the eonceptions and aims of the new Organisation, and in its machinery.

The most perfect plan and organization will not work, however, without finance and public support, and these must be based on public approval.

Another point of equal importance is the question of priorities. It is essential that the Organisation should be able to secure the needed equipment, after it has acquired the adequate finance. Teaching and research cannot be done without apparatus, scientific literature, and communications.

Men of science throughout the world hope that the Conference will have every success, and that, as a result of the discussions, a new Organisation will be established which will strengthen existing scientific collaboration and create new links where they are needed.

\section{SCIENCE AND THE UNITED NATIONS By Dr. JULIAN HUXLEY, F.R.S.}

THE proposals for the new United Nations Educational and Cultural Organisation were first put forward by the Conference of Allied Ministers of Education, which has sat in London since 1941, and in some of its later work was assisted by a delegation from the United Nations. This body was originally concerned with the immediate and essentially short-term task of securing the educational and cultural reconstruction of those parts of Europe and Asia which had suffered cultural distortion or destruction at the hands of the Axis Powers; and in April 1944 it formulated proposals designed to meet these needs. At San Francisco, however, this aim was extended and generalized, and it was proposed that a permanent special agency of the United Nations, devoted to educational and cultural tasks, should be established. The present Conference is engaged on the problems of giving final form to the draft charter of the Organisation put forward by the Allied Education Ministers, and broadly outlining its main aims and functions and of delimiting its field of action; after which it will set up an interim commission to work out details and to prepare the ground for the first full Conference to be held about a year hence.

Another historical point is also relevant. Since the original sponsoring body was a Conference of Education Ministers, the present Conference is one of delegations appointed by the Ministries of Education of the United Nations, convened by the British Ministry of Education, and presided over by the British Education Minister. Further, the emphasis in the original proposals was largely upon education. Some stress was later laid on culture, and the word 'Cultural' was included in the proposed title; but in spite of the fact that the Allied Education Ministers had a sub-committee to deal with scientific questions, science received less consideration, and proposals to include the word 'Scientific' in the title were at first rejected.

The Ministry of Education has now invited comments from a large number of bodies concerned with the educational, cultural and scientific life of Britain, and undoubtedly the replies of the scientific bodies will have ensured that the fullest consideration will be given by the British Delegation, and may we assume by the Conference as a whole, to the claims of science. However, there is no harm in rehearsing here some of the considerations which occur to most men of science who have given thought to this important subject.

In the first place, they consider it essential that the word 'Science' or 'Scientific' should occur in the title of the Organisation-that, in transatlantic phrase, the Conference should put the $\mathrm{S}$ in UNESCO. Opposition to this appears to come from two quarters 
- from certain educational circles who fear that the educational side of the new Organisation might come to be overshadowed by the seientific side; and from certain scientific quarters who dislike the idea that science is not 'cultural'. However, although of course 'culture' is a term of such loose definition that it may be stretched to include the totality of man's social activities, it is customarily used to include the humanities, literature and the arts, and in contradistinction to science. Further, even if culture in a partially restricted sense ean be taken to include pure science, it is difficult for most people to envisage applied science and technology as falling within its sphere. Finally, if culture be enlarged to include science, it should, by the same token, include education as well. Thus, on every ground it would appear right to call the new Organisation either simply ' $\mathrm{Cul}$ tural', or else 'Educational, Scientific and Cultural'.

However, the question of organization is more important than that of nomenclature. Here, too, most men of science are agreed that it is essential that a separate and relatively autonomous division devoted to the sciences and their application should be set up within the Organisation. There would presumably be other equivalent divisions dealing with education and with culture in the sense previously mentioned; in addition, a further division has been suggested in some quarters to deal with the "General Dissemination of Ideas", that is, the international aspects of the press, radio, cinema and the like, and laws concerning freedom of conscience, speech and assembly.

Each division should then have its own assistant director-general, its own secretariat, its own share of the general budget, and its own representation on the Council or other executive body of the entire Organisation. Such a council, with the directorgeneral of the United Nations Educational and Cultural Organisation as its chairman, and again its own share of the secretariat, would consider questions of general policy and the co-ordination of work between the separate divisions; but most of the actual work of the United Nations Educational and Cultural Organisation would be carried out by the separate divisions.

A subsidiary question remains. Should there be two scientific divisions, dealing with the natural and social sciences respectively; or only one, dealing with both ? There is a good deal to be said on both sides. But there is one consideration which is perhaps of an over-riding nature. The time appears to be ripe for extending scientific methods into many fields of social and economic life, both in respect to their study and to their practical direction and control, and for associating workers in the natural sciences with social and economic policy (witness the success of the application of scientific method in so-called 'operational research', in the social activity we call 'war'). If this be accepted, then it would seem important to make the attempt to unite the social and natural sciences and their applications within a single division : if this should prove impracticable, it would be easier to split a single division into two than to combine two separate divisions, each with its own outlook and traditions, its own amour propre, its own staff, into one.

There will clearly need to be considerable liaison between the separate divisions of the United. Nations Educational and Cultural Organisation (a liaison which will presumably need to be co-ordinated from above by the executive board, and to be effected horizontally between the divisions). Thus the scientific division will be deeply concerned about the place allotted to science at all levels of education, and about the methods of scientific teaching, as well as with the popularization of science by press, radio, etc. ; and in so far as the cultural division deals with philosophy and history, it will be concerned about the application of methodology of science to these and similar subjects.

In another article Mr. Crowther deals with some of the specific projects which the scientific division might undertake. Here let me merely sketch its main possible functions. In the first place, it should assist, stimulate, and co-ordinate the activities of existing international bodies in science-such as the international scientific unions, the international work in locust control, etc. Secondly, where some field is inadequately covered, or not at all, by existing international agencies, it should either promote such an agency or itself initiate and carry out the necessary survey and research. Thirdly, it should assist and promote the speediest possible diffusion of new scientific knowledge and ideas-by exchange of books, periodicals and reports ; by promoting rapid publication; by improved facilities for translation, abstracting, and providing reviews; by promoting special meetings of scientific workers to discuss pure scientific problems (notably perhaps in rapidly growing 'borderline' fields) and urgent practical applications of science; and in other ways. Fourthly, it should assist and promote the exchange of scientific personnel at every level-students, especially research students ; teachers, both in schools and universities ; mature research workers; etc. Fifthly, it should promote world science by assisting the growth of science in countries in which it is quantitatively or qualitatively under-developed-by helping in the provision of books and periodicals and apparatus, by travelling scholarships, research studentships and professorships in both directions, and above all by helping scientific workers in these countries to have speedy access to new scientific methods and results in the rest of the world. The success of the British Scientific Mission to China shows what can be done in this field by bilateral action : this would be multiplied many-fold by proper international organization.

So much for a United Nations Educational and Cultural Organisation. But it must be emphasized that, however satisfactory the place of science in this Organisation, there will remain other important functions for science to perform in the international sphere.

Let us recall the general organization proposed for the United Nations. In addition to the General Assembly, corresponding to the Assembly of the League of Nations, there are three Councils directing policy at the highest level. The Security Couneil will operate in the political and military field, with special reference to the preservation of peace. The Trusteeship Council will deal with what were called Mandated Territories under the League, and other similar problems. And the Economic and Social Advisory Council, as its name implies, will be concerned with all other fields in which it is hoped to secure international cooperation.

In this section of international affairs, a number of "Specialized Agencies", to quote the United Nations Charter, have been or will be set up to deal with particular fields. The United Nations Educational and Cultural Organisation is one of these; there are also in existence the International 
Bank and the International Monetary Fund, dealing with long-term and short-term problems respectively in the financial field, and the United Nations Food and Agriculture Organisation; it is proposed to set up a United Nations Health Organisation in the near future; and the International Labour Office has just decided to divest itself formally of its original connexion with the League and to seek to enter into relation with the United Nations Organisation. It is proposed that all the United Nations agencies of this type should be "brought into relationship" with the Social and Economic Advisory Council; and many people hope that it may be possible to do the same with the International Labour Office.

The precise relationship between the special agencies and the Economic and Social Advisory Council remains to be determined. While there is no suggestion that they shall be mere organs of the Council, it seems clear that they must be subordinate in the sense that they will be on a lower hierarchical level of the General United Nations Organisation; further (with the exception of the International Bank and Monetary Fund, which will be self-supporting) they might perhaps with advantage be directly financed by it through a block grant from the general funds of the United Nations*.

With this proposed set-up in mind, it becomes clear that the United Nations Educational and Cultural Organisation, however important and adequate a role is assigned in it to science, cannot cover all the scientific functions which the United Nations Organisation should exert. In the first place, since a United Nations Educational and Cultural Organisation will be in relationship with the Economic and Social Advisory Council, it cannot be expected to play any, or any considerable, part in relation to the Security and Trusteeship Councils. Secondly, since other special organizations operating in relationship with the Economic and Social Advisory Council have scientific aspects, notably the Food and Agriculture Organisation and the Health Organisation, some machinery is required for co-ordinating scientific policy and for allotting scientific functions as between the different special organizations ; and this can only be done at the level of the Economic and Social Advisory Council. And thirdly, the Economic and Social Advisory Council, the Security Council, and the Trusteeship Council will themselves undoubtedly require scientific advice on policy.

Thus while seientific work of an extensive type, involving either the eo-ordination and assistance or the actual promotion of many detailed and concrete schemes, will fall to the share of the United Nations Educational and Cultural Organisation, and special applications of science to that of the Food and Health and the Agricultural Organisations (and perhaps of the International Labour Office also), intensive scientific work, involving advice on and guidance of policy, will be required at the higher or Council level.

This, it may be suggested, would best be achieved. by the formation of special scientific committees of the three Councils, which would combine advisory

* The converse procedure, by which the special organizations would be independently financed, by separate grants from separate member nations, was adopted for the special organizations of the League, namely, the Institute of Intellectual co-operation and the Internationa not guarantee that all member nations will take part in the work of the special organizations, there is less guarantee of nations being in arrears with special contributions than with a general contribution to the United Nations, and it may
conditions to their contributions. with policy-making functions. In order to obtain the services of the highest-ranking men of science, these Committees should not be drawn from the permanent staff of the United Nations, but should meet at intervals of a few months, presumably in relation to the regular meetings of the Economic and Social Advisory Council and the Trusteeship Council ; and for the Security Council, which will be in permanent session, at such times as are proved convenient. An amount of preparatory work on scientific subjects might also be required, which could of course be carried out by a few members of the permanent secretariats of the Councils.

As regards the composition of the seientific committees, the case of the Security Council is the simpler, since the scientific problems with which it is or ought to be concerned are less varied. One may suggest that a committee of 10-15 members would suffice. Owing to the technical and often secret nature of the scientific problems involved, the members would presumably have to be drawn from the permanent scientific advisers of the Armed Services of the eleven nations composing the Council, or from independent men of science who had been closely associated with scientific advisory work for their Service Departments.

It may further be suggested, in view of the overwhelming importance of science in various questions with which the Security Council will inevitably be concerned (such as the control of atomic weapons and the regulation or inspection of pure scientific work in atomic physics), that a proportion of the members of its scientific committee who by virtue of their training are able to understand both the immediate and the long-range implications of scientific ideas and applications, should actually sit at the meetings of the Council itself, as observers taking part in its discussions.

In the case of the Economic and Social Advisory Council, the scientific committee will in the first place require to be more numerous, in view of the numbers of fields of science to be covered-say 15-25 members ; normally much of its work might perhaps be best carried out by sub-committees. Secondly, it will not be so imperative that its members should be drawn from among the permanent scientific staff of member nations; a considerable proportion at least could more profitably be selected from independent men of science in universities or research institutes. Among the separate subjects on which their advice would be sought would be the place of science in education, the encouragement of scientific research in general, the application of science to health, agriculture, housing, generation of power, population policy, etc.; but their most important function would be to make the Economic and Social Advisory Council aware of the broader implications of scientific advance for social and economic welfare.

The scientific committee of the Trusteeship Council will presumably have to cover fields such as anthropology, tropical agriculture and medicine, soil erosion, etc., and might include 12-20 members.

The assumption of such important roles by science in the international sphere has certain implications for its future role in national affairs. In Britain, the most obvious need would seem to be the strengthening of the Scientific Advisory Committee to the Cabinet, and the provision of a national scientific secretariat in the Cabinet Office. In addition, the internal apparatus of scientific research councils needs to be 
reviewed, to see whether there are not any gaps to be filled in it; some men of science, for example, consider that the existing Research Councils (including, of course, the Department for Scientific and Industrial Research) might profitably be supplemented by the creation of a Biological Research Couneil, which, in addition to covering a wide field of research which is not at present adequately covered by the existing Councils, could take over under unified control some of the biological projects now dispersed among the others.

To return to the international sphere, it is of great importance that men of science should realize the need for 'high-level' representation of science in the United Nations Organisation, in direct relation to the three Councils. This is all the more urgent since not only is such a function of science in no way covered by the United Nations Educational and Cultural Organisation, still less by the other special agencies, but it has not yet been envisaged by the Preparatory Commission of the United Nations Organisation (see the recently published Report of its Executive Committee) - in spite of the fact that the first session of the General Assembly of the United Nations is to meet in London in January.

\section{WORLD CO-OPERATION IN SCIENCE}

\section{By J. G. CROWTHER}

$\mathrm{T}$ HE present Conference and proposals for educational, scientific and cultural co-operation have arisen, in the first instance, through the devastation of war. When countries were invaded, millions of men and women retreated before the enemy, and hundreds of thousands came to the United Kingdom. The children and the young needed succour and education, and through this, the Ministers of Education of the occupied countries met to organize assistance. From immediate help for refugees, they passed to plans for assisting the cultural life of their countries after liberation, and then to the promotion of cultural co-operation on a new world scale. There were the three stages of relief, rehabilitation, and the advancement of civilization.

Each of these stages has its special problems. In the educational field, books and elementary teaching equipment are the most important mass need. The urgency of the provision of text-books, pencils, desks, paper, and the other elementary things is extreme. In principle, it does not seem to be a very difficult problem. The great difficulties that arise in practice are shortage of raw materials, labour, machinery and the organization of production. Their solution would be straightforward, if economic conditions were easy.

In the field of rehabilitation concerned with more advanced institutions, the problems are much less clear. How should a restored physics research laboratory be equipped ? Should its old equipment be looked for, and put back; or should modern up-to-date equipment be installed? Should the balance of selection of new equipment be the same as the old ?

It is evident that rehabilitation of advanced and university laboratories is a complex and highly technical job. A pooling of world information on equip- ment and a pooling of world opinion on methods of equipping scientific institutions are required.

The Conference of Allied Ministers of Education, which gave rise to the present Conference, has already done a considerable amount of work on the compilation of inventories of equipment for a wide range of teaching and academic laboratories. The various inventories for chemical, physical, agricultural, medical and engineering laboratories have been compiled by committees of men of science of various nationalities.

It is possible that their labours contain the germ of the rationalization of scientific equipment. The new organization should extend this work.

A second needed activity is the survey of the world needs of scientific equipment. In the process of its work, the Science Commission of the Conference of Allied Ministers of Education had occasion to estimate the value of scientific equipment that existed in nine occupied European countries. They found that it was of the order of $£ 100,000,000$. There is a striking lack of economic data of this kind. No one ever seems to have asked before exactly what the world needs of scientific equipment might be. It is evident that such data are essential for the planning of the massproduction of scientific equipment at low prices. For example, steam-engines of various kinds are needed for engineering laboratories. Their price varies greatly according to whether they are needed in lots of five or five hundred. The cost of scientific rehabilitation could be greatly reduced if the world manufacture of scientific equipment could be to some extent rationalized.

The world Organisation could promote similar action with regard to scientific and engineering textbooks. For example, a uniform system of units might be introduced. A common denominator for the decimal and the foot-pound systems would enable men of science and engineers to refer to books in any language, without the confusion of incommensurable sizes and units.

Another direction in which there is need for positive innovation is in the types of research fellow. ship. Something in the nature of 'research visitors' should be invented. There is a great need for the provision of small sums to enable research workers to make short visits for periods of a week to three months, to demonstrate or learn a new technique, or to travel to a laboratory where there is unique apparatus, in order to make a special experiment. There is very much less resource for this kind of journey than for studentships and fellowships of one year's minimum duration. The promotion of contact between men of science should be much more flexible and varied. The new Organisation should compare what various countries are doing in this way, make a list of world resources for means for travel, and direct the attention of particularly good systems that exist in one country to the notice of others.

There is general agreement that the small scientific conference of specialists should be encouraged. Allied to this development is the provision of accommodation for scientific workers and men of learning travelling about the world. A chain of houses in the leading cities and centres of the world should be developed, so that a man of science going from one country to another can be sure of a comfortable, informed and inexpensive reception everywhere. A pooling of the ideas of the nations on this topic might lead to interesting innovations.

Yet another direction for development is in the 